J. Dairy Sci. 98:8505-8514

http://dx.doi.org/10.3168/jds.2015-9959

(C) American Dairy Science Association ${ }^{\circledR}, 2015$.

\title{
Water-lactose behavior as a function of concentration and presence of lactic acid in lactose model systems
}

\author{
Rangani Wijayasinghe, Todor Vasiljevic, and Jayani Chandrapala ${ }^{1}$ \\ Advanced Food Systems Research Unit, College of Health and Biomedicine, Victoria University, Werribee campus, Melbourne, \\ VIC 8001, Australia
}

\begin{abstract}
The presence of high amounts of lactic acid in acid whey restricts its ability to be further processed because lactose appears to remain in its amorphous form. A systematic study is lacking in this regard especially during the concentration step. Hence, the main aim of the study was to establish the structure and behavior of water molecules surrounding lactose in the presence of $1 \%$ (wt/wt) lactic acid at a concentration up to $50 \%$ (wt/wt). Furthermore, the crystallization nature of freeze-dried lactose with or without lactic acid was established using differential scanning calorimetry and Fourier transform infrared spectroscopy. Two mechanisms were proposed to describe the behavior of water molecules around lactose molecules during the concentration of pure lactose and lactose solutions with lactic acid. Pure lactose solution exhibited a water evaporation enthalpy of $\sim 679 \mathrm{~J} \cdot \mathrm{g}^{-1}$, whereas lactose + lactic acid solution resulted in $\sim 965 \mathrm{~J} \cdot \mathrm{g}^{-1}$ at a $50 \%$ (wt/wt) concentration. This indicates a greater energy requirement for water removal around lactose in the presence of lactic acid. Higher crystallization temperatures were observed with the presence of lactic acid, indicating a delay in crystallization. Furthermore, less crystalline lactose $(\sim 12 \%)$ was obtained in the presence of lactic acid, indicating high amorphous nature compared with pure lactose where $\sim 50 \%$ crystallinity was obtained. The Fourier transform infrared spectra revealed that the strong hydration layer consisting lactic acid and $\mathrm{H}_{3} \mathrm{O}^{+}$ions surrounded lactose molecules via strong $\mathrm{H}$ bonds, which restricted water mobility, induced a change in structure of lactose, or both, creating unfavorable conditions for lactose crystallization. Thus, partial or complete removal of lactic acid from acid whey may be the first step toward improving the ability of acid whey to be processed.
\end{abstract}

Key words: lactose, acid whey, lactic acid

Received June 14, 2015.

Accepted September 2, 2015.

${ }^{1}$ Corresponding author: Janage.Chandrapala@vu.edu.au

\section{INTRODUCTION}

Lactose is the major carbohydrate in milk and consequently one of the main components of whey streams. Whey is the serum or liquid portion of milk remaining after coagulation and casein removal. Moreover, this whey contains more than half of the nutrients in original whole milk (Vasiljevic and Jelen, 1999). Depending on the manufacturing process, whey has been classified into 2 major groups, namely sweet whey, which originates from hard cheese and rennet casein production, and acid whey with a $\mathrm{pH}$ of $\sim 4.5$ expelled during production of acid coagulated dairy products such as cream, ricotta, and cottage cheeses or strained (Greek style) yogurt (Schmidt et al., 1984). In the past, whey streams were disposed of by spreading onto the fields or simply dumping into the ocean. However, the presence of milk solids, mainly lactose in whey, created a significant environmental issue due to its high organic load and a high biological oxygen demand required for its decomposition. The only sustainable way to reduce this environmental effect has been to extract and concentrate solids from whey. Hence, sweet whey has been widely used for the production of different powders (lactose, whey proteins), which are currently used as ingredients in many food and pharmaceutical applications (Chandrapala et al., 2015).

In contrast to sweet whey, an industrial solution for acid whey processing has not been found likely due to its compositional difference (Chandrapala et al., 2015). Acid whey contains higher levels of minerals, but less proteins and lactose depending on different processing conditions, and more importantly, greater concentration of lactic acid than sweet whey (De Wit, 2001). Acid whey is considered a hard to process stream mainly due to failure of lactose to crystallize, which apparently remains in its amorphous form during concentration and thus hinders further processing. Amorphous lactose exists in a glassy, solid state or in syrup-like, super-cooled liquid state. The state transition of an amorphous solid is described by a second order known as glass transition $\left(\mathrm{T}_{\mathrm{g}}\right) ; \mathrm{T}_{\mathrm{g}}$ is defined as the temperature at which an amorphous system changes from glassy to the rub- 
bery state. This can either take place by increase in temperature or increase in the plasticizer amount (e.g., water content) or both. Molecular mobility is limited below $\mathrm{T}_{\mathrm{o}}$, whereas molecular mobility increases above $\mathrm{T}_{\mathrm{g}}$, resulting in a greater potential for chemical interactions between components. This in turn can substantially change structural properties (Bhandari, 2008).

Relative low sweetness, crystallization properties, flavor-emphasizing abilities, and protein stabilization properties make lactose an important ingredient for various food applications. The industrial extraction of lactose is traditionally achieved by concentration and crystallization of whey, whey permeates, or milk permeates. Whey is pasteurized and concentrated to about 60 to $65 \%$ (wt/wt) of TS by vacuum evaporation (De Wit, 2001). Consequently, the concentrated whey is subjected to rapid cooling followed by slow cooling to induce lactose nucleation and crystal growth, which are the main steps of the crystallization process. Subsequently, lactose crystals are separated by centrifugation or sent to spray drying. Although this process appears simple, the lactose recovery from whey depends on numerous factors such as the degree of supersaturation, solution temperature, viscosity, concentration of lactose, presence of minerals, presence of organic acids, and $\mathrm{pH}$ (Jelen and Coulter, 1973b; Bhargava and Jelen, 1996; Ganzle et al., 2008).

Whereas the presence of inorganic acids improves the rate of lactose crystallization, the presence of lactic acid appears to act as an inhibitor hindering the crystallization process (Jelen and Coulter, 1973a; Ganzle et al., 2008). Increasing the lactic acid concentration from 1 to $20 \%$ (wt/wt) decreased the yield of spray-dried lactose powders (Saffari and Langrish, 2014). Furthermore, presence of minerals in lactose solutions may have a contradicting outcome, resulting in an enhanced or diminished crystallization rate depending on the concentration and the type of the salt present (Jelen and Coulter, 1973a). A change in solubility of lactose was assumed to be the cause for the crystallization behavior changes in the presence of impurities (Mullin, 1979). These solubility changes can be due to structural changes of water molecules in bulk water. The presence of ions with high charge density $\left(\mathrm{Ca}^{2+}, \mathrm{Ba}^{2+}\right)$ are believed to orient the water structure due to their ability to electrostatically organize the structure of water. However, some ions with low charge density $\left(\mathrm{Cl}^{-}, \mathrm{Br}^{-}\right.$, $\mathrm{I}^{-}$) led to perturbation and structure breaking of water molecules (Von Hippel and Schleich, 1969). Hence, changes in water structure directly affect the solubility and thereby the supersaturation of the lactose solution, which is one of the leading factors governing the lactose crystallization (Mullin, 1979).
Current understanding highlights the importance of the presence of minerals, whey proteins, and lactic acid for elucidating kinetics of lactose crystallization. Because one of the major compositional differences between acid and sweet whey is the presence of lactic acid, it would be beneficial to establish the influence of the presence of lactic acid toward the change in the behavior of water and thereby predict the crystallization behavior of lactose model solutions. A systematic study is lacking in this regard especially during the concentration step, because this is also considered a crucial step during processing of acid whey and thus recovery of lactose crystals. Hence, the present study aimed at establishing the structure and behavior of water molecules surrounding lactose as a function of concentration (15 to $50 \% \mathrm{wt} / \mathrm{wt}$ ) in the presence or absence of lactic acid. Furthermore, the crystallization nature of lactose obtained from 50\% (wt/wt) lactose solutions with or without lactic acid was established.

\section{MATERIALS AND METHODS}

\section{Materials}

A commercial food-grade lactose powder and an analytical-grade lactic acid solution were obtained from Murray Goulburn Co-operative Co. Ltd. (Brunswick, Australia) and Sigma-Aldrich Pvt. Ltd. (Castle Hill, NSW, Australia), respectively. Milli-Q water was used at all times for the preparation of solutions.

\section{Preparation of Solutions}

Lactose powder $(5 \mathrm{~g})$ was dissolved in $95 \mathrm{~g}$ of Milli-Q water at room temperature to obtain a $5 \%$ (wt/wt) lactose solution. Lactose plus lactic acid (lactose + lactic acid) solution was prepared by the addition of $1 \mathrm{~g}$ of lactic acid to the $5 \mathrm{~g}$ of lactose powder and made up to a total weight of $100 \mathrm{~g}$. Concentrations of $5 \%$ and $1 \%$ (wt/wt) were selected to imitate the lactose and lactic acid concentrations present in acid whey, respectively. The solutions were stirred using a magnetic stirrer for about $30 \mathrm{~min}$ until clear solutions were obtained with no visually observable powder particles. All the solutions were filtered using $0.45-\mu \mathrm{m}$ Whatman filter papers to remove any undissolved particles. The $\mathrm{pH}$ of the lactose and lactose + lactic acid solutions were 5.8 and 4.9 , respectively.

\section{Concentration of Lactose and Lactose + Lactic Acid Solutions}

Concentration of lactose and lactose + lactic acid solutions was performed using a rotary evaporator 
(EYELA, Rikakikai Co. Ltd., Tokyo, Japan). The temperature of the rotary evaporator water bath was adjusted to $55^{\circ} \mathrm{C}$ to imitate the industrial conditions. The stock solutions were concentrated to $15,20,30,40$, and $50 \%$ (wt/wt) TS.

Refractometry measurements were performed by determining the refractive index (Brix value) using a laboratory refractometer (Atago Abbe, Tokyo, Japan) for concentration determinations.

\section{Freeze-Drying}

Final $50 \%$ (wt/wt) concentrated solutions of lactose and lactose + lactic acid were poured into 15-mL Eppendorf tubes. All samples were frozen at $-20^{\circ} \mathrm{C}$ for $24 \mathrm{~h}$ and then freeze-dried (Dynavac FD 300, Dynavac Engineering Pty, Belmont, Australia) for $72 \mathrm{~h}$. The residual water was removed by keeping the samples in a vacuum desiccator over $\mathrm{P}_{2} \mathrm{O}_{5}$ at room temperature for at least $5 \mathrm{~d}$.

\section{Differential Scanning Calorimetry}

Concentrated lactose and lactose + lactic acid solutions were transferred into preweighed differential scanning calorimetry (DSC) aluminum pans $(40 \mu \mathrm{L}$; ME26763, Mettler Toledo, Schwerzenbach, Switzerland) and the pans were hermitically sealed. Subsequently samples were transferred into a DSC (DSC 1 STAR $^{\mathrm{e}}$ System, gas controller, GC 200, Mettler Toledo). An empty pan was used as a reference. The DSC was calibrated using indium (melting point, $156.6^{\circ} \mathrm{C}$ and $\Delta \mathrm{H}_{\mathrm{m}}$, $28.45 \mathrm{~J} \cdot \mathrm{g}^{-1}$ ). All samples were scanned with a starting temperature of $25^{\circ} \mathrm{C}$ and end temperature of $280^{\circ} \mathrm{C}$ at a heating rate of $5^{\circ} \mathrm{C} \cdot \mathrm{min}^{-1}$, which was a modified version of the method described by Haque and Roos (2006). Onset and end-set temperatures of water evaporation and related enthalpies (area under the curves) were analyzed using $\mathrm{STAR}^{\mathrm{e}}$ thermal analysis software, 12.1 (Mettler Toledo).

Freeze-dried samples were also subjected to the same program with slight modifications in which samples were scanned to $120^{\circ} \mathrm{C}$ at a heating rate of $10^{\circ} \mathrm{C} \cdot \mathrm{min}^{-1}$, then cooled at $5^{\circ} \mathrm{C} \cdot \mathrm{min}^{-1}$ to $25^{\circ} \mathrm{C}$, followed by a second heating scan at $10^{\circ} \mathrm{C} \cdot \mathrm{min}^{-1}$ to $200^{\circ} \mathrm{C}$. The scans were normalized by the system according to the sample mass, and the integrated peak energies were used to compare the differing degrees of crystallinity.

\section{Fourier Transform Infrared Spectroscopy}

The Fourier transform infrared spectroscopy (FTIR) spectra of pure lactose and lactose + lactic acid solutions were obtained in the range of 4,000 to $400 \mathrm{~cm}^{-1}$ imme- diately after achieving relevant concentrations from 15 to 50\% (wt/wt) using FTIR (Shimadzu IR Affinity-1, Shimadzu Corp., Kyoto, Japan) with the combined software of IR Solution (Shimadzu Corp.). Sample spectra were collected in the absorbance mode after background detraction. Each spectrum was a result of an average of 32 scans recorded at $4 \mathrm{~cm}^{-1}$ resolution. The spectra were analyzed over the wavelength ranges of interest 4,000 to $2,600 \mathrm{~cm}^{-1}, 2,000$ to $950 \mathrm{~cm}^{-1}$, and 1,200 to $950 \mathrm{~cm}^{-1}$.

\section{Statistical Analysis}

All experiments were arranged in a randomized split plot block design, in which lactose concentration (5 levels) was the main factor and the replication served as block. The whole design was replicated with a subsequent subsampling resulting in at least 4 independent observations $(\mathrm{n} \geq 4)$. The least squares mean (LSM) was used to differentiate the means with the preset probability at $P<0.05$.

\section{RESULTS AND DISCUSSION}

\section{Behavior of Water Molecules Around Lactose in the Presence of Lactic Acid as a Function of Concentration}

Concentrating lactose solutions by evaporation usually results in formation of highly viscous, metastable, amorphous lactose concentrate (Roos and Karel, 1990). Thermographic analyses of lactose solutions during concentration from 15 to $50 \%$ (wt/wt) are shown in Figure 1A. The obtained thermograms resulted an endothermic peak around 130 to $140^{\circ} \mathrm{C}$, which can be attributed to removal of water molecules from the lactose solutions (Yazdanpanah and Langrish, 2011). The change in lactose concentration did not affect the recorded onset, end-set, and peak temperatures $(P>0.05)$. However, as expected, increasing concentration significantly $(P<$ 0.05 ) lowered the total enthalpies of dehydration (Table 1). As shown, $15 \%$ (wt/wt) pure lactose solution had an enthalpy of $\sim 1,588 \mathrm{~J} \cdot \mathrm{g}^{-1}$. During concentration, the enthalpy declined resulting in a value of $\sim 679 \mathrm{~J} \cdot \mathrm{g}^{-1}$ for the $50 \%$ (wt/wt) lactose solution. The amount of free water available for removal was reduced by $35 \%$ when increasing the lactose concentration from 15 to $50 \%$ (wt/wt). However, an almost 57\% reduction in total enthalpy was observed, which indicated that reduced availability of free water molecules for dehydration was not the only cause for the decreased enthalpy. During concentration, physical changes may occur in biological materials (i.e., lactose), which in turn results in different water molecular mobilities due to varying degrees 

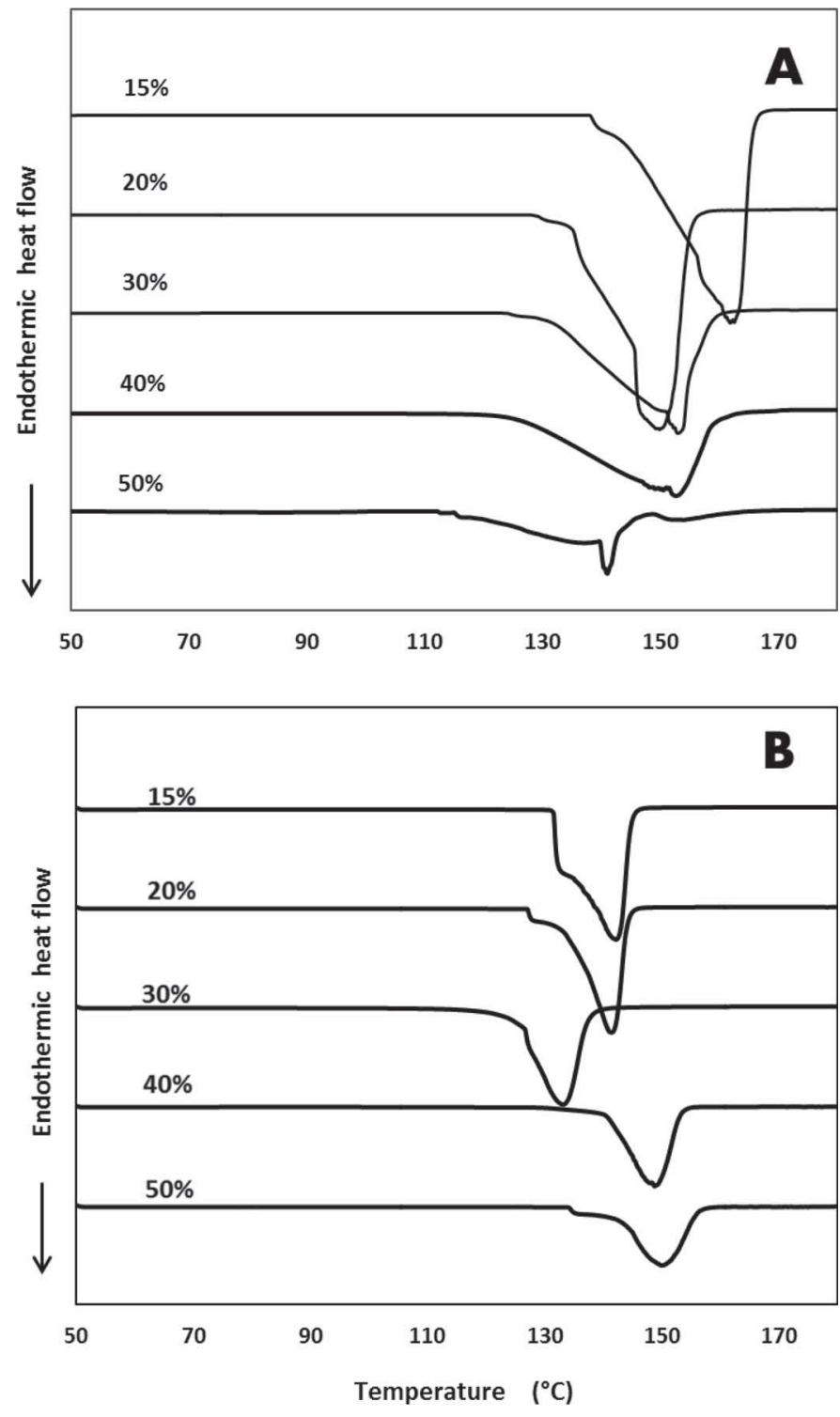

Figure 1. Dynamic differential scanning calorimetry curves for lactose solutions as a function of concentration (A) without lactic acid, and (B) in the presence of $1 \%(\mathrm{wt} / \mathrm{wt})$ lactic acid.

of associations (Roos and Karel, 1990). Variances in intermolecular distances and order of molecular arrangements may also lead to differences in potential energy (Anslyn and Dougherty, 2006).

Water dehydration behavior of lactose changed substantially upon addition of lactic acid. Lactic acid is miscible with water and has the ability to attract and hold water molecules from the surrounding environment (Jamshidian et al., 2010). Increasing the concentration of lactose + lactic acid solution had no observable $(P$ $>0.05$ ) effect on the onset, end-set, and peak temperatures. In contrast, the water evaporation enthalpies were again significantly $(P<0.05)$ reduced (Table 1$)$.
For example, $15 \%$ (wt/wt) lactose + lactic acid solution had an enthalpy of $\sim 1,621 \mathrm{~J} \cdot \mathrm{g}^{-1}$, whereas an enthalpy $\sim 965 \mathrm{~J} \cdot \mathrm{g}^{-1}$ was observed for the $50 \%$ (wt/wt) lactose + lactic acid solution. Furthermore, these enthalpies were higher than those of pure lactose solutions, which further highlighted the fact that reduced availability of free water molecules for removal with increase in concentration was not the sole factor, but molecular arrangements and mobility could also play an important role. Lactic acid is a highly hydrophilic compound that strongly interacts with water. This in turn induces changes in the structural associations and mobility of adjacent water molecules, extending distances between lactose molecules. In addition, reactivity of water molecules may be changed due to strong attractions with lactic acid (Reid and Fennema, 2008). Lactic acid forms hydrated $\mathrm{H}_{3} \mathrm{O}^{+}$ions with water via exceptionally strong $\mathrm{H}$ bonds (Belitz et al., 2009). Hence, rise in enthalpies of lactose + lactic acid solutions indicate that a high energy was required to remove water molecules from lactose solutions in the presence of lactic acid.

Furthermore, the addition of lactic acid to the lactose solution decreased the $\mathrm{pH}$ from 5.8 to 4.9, which resulted in a $\sim 15 \%$ reduction in $\mathrm{pH}$ and may affect the overall crystallization behavior of lactose. However, Jelen and Coulter (1973a) found that these $\mathrm{pH}$ changes with the presence of lactic acid have minor contributions in the overall lactose crystallization process. In addition, the present study showed no change in $\mathrm{pH}$ during the concentration process, whereas significant changes in the evaporation behavior of water molecules were observed with the presence of lactic acid. This further highlights the fact that $\mathrm{pH}$ plays a minor role during lactose crystallization.

\section{Glass Transition and Crystallinity of Freeze-Dried Samples}

Thermal analysis of concentrated liquid samples showed that presence of lactic acid had a great influence on the removal of water from lactose. This in turn might have led to changes in glass transition temperature $\left(\mathrm{T}_{\mathrm{g}}\right)$ and crystallinity of lactose. Hence, freezedried lactose and lactose + lactic acid samples were tested for the changes in their crystallinity and glass transition temperatures by DSC (Figure 2).

An endothermic relaxation peak associated with the glass transition of pure lactose was observed even in an immediate rescan of samples (Figure 2). The recorded glass transition temperature for the pure lactose was $105.2^{\circ} \mathrm{C}$. This value is similar to the values obtained by Omar and Roos (2007) reported as $105.5^{\circ} \mathrm{C}$, but a slightly higher than the value recorded by Roos and Karel (1990) of $\sim 101.2^{\circ} \mathrm{C}$. The varying absolute val- 
Table 1. Onset, end-set, and peak temperatures and enthalpy of lactose solutions as a function of concentration and presence of lactic acid

\begin{tabular}{lcccc}
\hline & $\begin{array}{c}\text { Onset } \\
\text { temperature } \\
\left({ }^{\circ} \mathrm{C}\right)\end{array}$ & $\begin{array}{c}\text { End-set } \\
\text { temperature } \\
\left({ }^{\circ} \mathrm{C}\right)\end{array}$ & $\begin{array}{c}\text { Peak } \\
\text { value } \\
\left({ }^{\circ} \mathrm{C}\right)\end{array}$ & $\begin{array}{c}\text { Enthalpy } \\
\left(\mathrm{J} \cdot \mathrm{g}^{-1}\right)\end{array}$ \\
\hline Lactose & & & & \\
15 & 135.04 & 148.16 & 138.80 & $1,588.68^{\mathrm{a}}$ \\
20 & 129.42 & 145.55 & 135.80 & $1,479.04^{\mathrm{a}}$ \\
30 & 140.37 & 157.89 & 150.61 & $1,002.02^{\mathrm{b}}$ \\
40 & 140.12 & 155.09 & 147.59 & $1,000.69^{\mathrm{b}}$ \\
50 & 133.49 & 142.35 & 134.01 & $679.03^{\mathrm{c}}$ \\
Lactose + lactic acid & & & & \\
15 & 128.48 & 137.29 & 130.66 & $1,621.51^{\mathrm{a}}$ \\
20 & 121.03 & 130.54 & 124.05 & $1,465.90^{\mathrm{a}}$ \\
30 & 129.41 & 139.85 & 131.63 & $1,376.33^{\mathrm{a}}$ \\
40 & 134.67 & 146.84 & 140.00 & $845.17^{\mathrm{cb}}$ \\
50 & 129.20 & 144.17 & 136.29 & $965.09^{\mathrm{b}}$ \\
SEM $^{1}$ & 14.17 & 5.28 & 5.09 & 101.61 \\
\hline
\end{tabular}

${ }^{\mathrm{a}-\mathrm{c}}$ Means in the same column with different superscripts are significantly different $(P<0.05)$.

Values are means of at least 4 independent observations $(n \geq 4)$.

${ }^{1}$ SEM denotes pooled standard error of the mean, $P<0.05$.

ues within studies highlight the different nature of the experiments and the compositional variations of the samples. Lactic acid is a highly hygroscopic compound that exists in liquid state at room temperature and has a very low $\mathrm{T}_{\mathrm{g}}$ value, about $-60^{\circ} \mathrm{C}$ (Maltini et al., 1967). The temperature range that was used within the present study (due to limitations of the instrument) did not record a $\mathrm{T}_{\mathrm{g}}$ value for lactose + lactic acid sample, indicating that $\mathrm{T}_{\mathrm{g}}$ of lactose might have probably occurred at a temperature below the level of instrument detection due to the presence of lactic acid. Thus, the addition of lactic acid likely led to a decrease in $\mathrm{T}_{\mathrm{g}}$ of lactose. This observation is in line with Bhandari (2008) and Saffari and Langrish (2014). Vaporized wa-

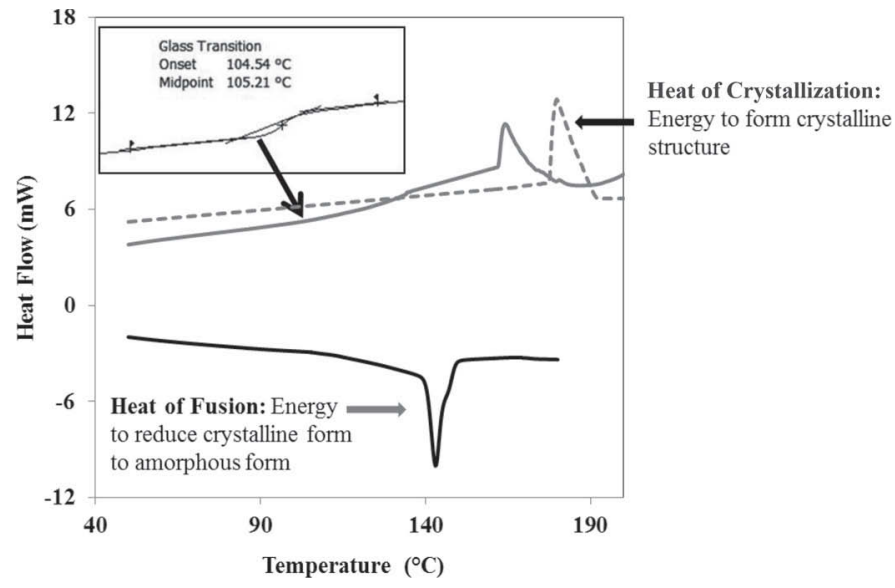

Figure 2. Dynamic differential scanning calorimetry curves for freeze-dried lactose (gray solid) and lactose $+1 \%$ (wt/wt) lactic acid (gray dashed) and lactose monohydrate (solid black) in the temperature region of 50 to $200^{\circ} \mathrm{C}$. ter molecules may easily be absorbed by the powders due to the hygroscopic nature of lactic acid, which consequently may lead to plasticization, thereby lowering the $\mathrm{T}_{\mathrm{g}}$ (Aubuchon and Thomas, 2007).

Exceeding $\mathrm{T}_{\mathrm{g}}$ of lactose results in dramatic changes in the flow properties of powders, and the time-dependent crystallization of lactose. The instant crystallization temperature $\left(\mathrm{T}_{\text {cr }}\right)$ of lactose measured using the DSC was $163.7^{\circ} \mathrm{C}$, whereas lactose + lactic acid appeared around $179.1^{\circ} \mathrm{C}$ (Figure 2). The reported $\mathrm{T}_{\text {cr }}$ of dry lactose varies in literature, depending on moisture content, DSC scanning rates, and type of DSC pan (sealed/ puncture; Haque and Roos, 2004). The presence of lactic acid led to higher crystallization temperatures showing a delay in crystallization. Furthermore, the onset and end-set temperatures of lactose crystallization were 161.7 and $170.6^{\circ} \mathrm{C}$, respectively, for pure lactose samples. When lactic acid was present, the onset and end-set temperatures were 177.0 and $188.9^{\circ} \mathrm{C}$, respectively. The broader peak observed in the thermograph of lactose + lactic acid shows an obvious difference in the crystallization temperature range between lactose and lactose + lactic acid. Lactose samples have crystallized within $\sim 9^{\circ} \mathrm{C}$, whereas the lactose + lactic acid sample showed a $\sim 12^{\circ} \mathrm{C}$ temperature window. A greater peak was observed by lactose + lactic acid sample in comparison to pure lactose indicating a large amorphous content (Chiou et al., 2008). In addition, the enthalpy associated with crystallization, termed heat of crystallization $\left(\Delta \mathrm{H}_{\mathrm{cr}}\right)$, can be used to quantify the amorphous content (Aubuchon and Thomas, 2007). The heat of

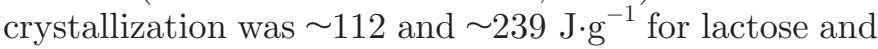
lactose + lactic acid, respectively. This clearly shows that more energy is required to induce lactose crystal- 
lization in the presence of $1 \%$ (wt/wt) lactic acid. In contrast, a decrease in heat of crystallization for spraydried lactose powders with increasing concentration of lactic acid was observed by Bhandari (2008) and Saffari and Langrish (2014). This may mostly be due to the different concentration range of lactic acid used, different drying techniques used, or both, in these studies.

In the present study, lactose monohydrate was used as $100 \%$ crystalline with an energy of $\sim 626 \mathrm{~J} \cdot \mathrm{g}^{-1}$. This was measured by subtraction of heat of crystallization from heat of fusion values (Chiou et al., 2008). Our freeze-dried lactose sample produced an average energy

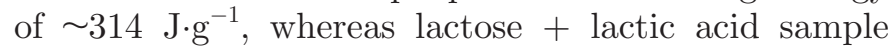
showed an average of $\sim 74 \mathrm{~J} \cdot \mathrm{g}^{-1}$. This shows that our freeze-dried lactose sample consisted of $\sim 50 \%$ crystalline lactose. Furthermore, in the presence of lactic acid the crystallinity of lactose declined down to $\sim 12 \%$. This reinforces our understanding that inability to process acid whey is due to presence of lactic acid as it prevents the crystallization of lactose.

\section{Fourier Transform Infrared Spectroscopy}

Above a certain temperature (glass transition temperature), amorphous lactose transfers through the rubbery zone into a crystalline state due to increased molecular mobilities and as a result of water plasticization. The results of thermographic analysis confirmed that the behavior of water molecules in lactose was substantially influenced by lactose concentration and presence of lactic acid. The presence of lactic acid hindered the evaporation of water molecules to a greater extent at 50\% (wt/wt) concentration as compared with other concentrations. Earlier, we hypothesized that this could possibly be due to certain structural changes of lactose in the presence of lactic acid, which could be identified by infrared spectroscopy. Fourier transform infrared spectroscopy is a simple and rapid technique that screens molecular vibrations shown by various compounds. Generally, the 1,200 to $800 \mathrm{~cm}^{-1}$ range is used to determine phase changes of carbohydrates as $\mathrm{C}-\mathrm{C}$ and $\mathrm{C}-\mathrm{O}$ stretching and vibrations are influenced by their physical state (Ottenhof et al., 2003). Similarly 3,600 to $3,200 \mathrm{~cm}^{-1}$ region is used to determine the structure of water around carbohydrate molecules.

Figure 3 shows the FTIR spectra of lactose with and without addition of lactic acid in the infrared range of 1,200 to $950 \mathrm{~cm}^{-1}$, respectively. Two prominent peaks originating around $1,040 \mathrm{~cm}^{-1}$ and $1,075 \mathrm{~cm}^{-1}$ were observed in the 20 to $40 \%$ (wt/wt) lactose solutions. The corresponding peaks were found to be associated with $\mathrm{C}-\mathrm{C}$ stretching vibrations and $\mathrm{C}-\mathrm{O}$ stretching of glucose molecule of lactose, respectively (Solis-Oba et al., 2011). On the other hand, these 2 peaks were almost
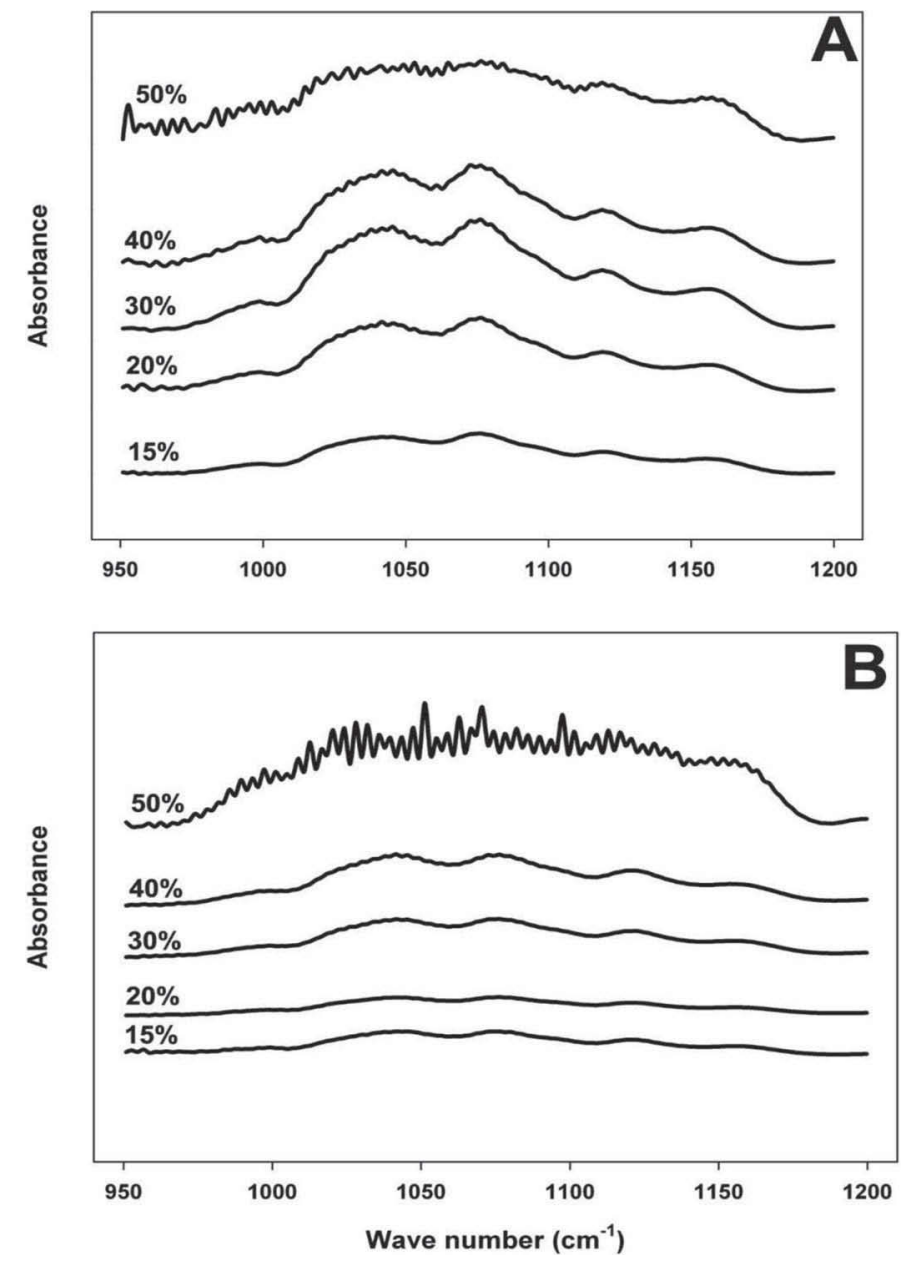

Figure 3. Fourier transform infrared spectra of the 1,200 to 950 $\mathrm{cm}^{-1}$ region in lactose (A) and lactose + lactic acid (B) as a function of concentration.

absent in the $50 \%$ (wt/wt) lactose solution (Figure 3A). During concentration, the intermolecular H-bonds become stronger between lactose and water molecules (Punitha et al., 2014), which consequently results in reduced stretching vibrations.

The addition of lactic acid led to further decline in intensities of the peaks around 1,040 and $1,075 \mathrm{~cm}^{-1}$ with respect to lactose solutions at all concentrations (Figure 3B). As explained previously, the formation of hydrated $\mathrm{H}_{3} \mathrm{O}^{+}$ions with strong $\mathrm{H}$ bonds in the presence of lactic acid may lead to this further disappearance of stretching vibrations. This effect was more pronounced with $50 \%$ (wt/wt) lactose + lactic acid solution as compared with lactose solution where the peaks were undefinable (Figure 3B). Furthermore, the poorly defined peaks within this range correspond to the presence of amorphous lactose (Islam and Langrish, 2010). This observation thus further highlights reduced crystallinity nature of lactose molecules in the pres- 
ence of lactic acid, which also confirms observations obtained by DSC.

A protruding peak around $1,650 \mathrm{~cm}^{-1}$ was observed for pure lactose solutions, which may correspond to the bending mode of water molecules (Velazquez et al., 2003). This peak appeared at all concentrations, although its intensity was reduced as a function of concentration (Figure 4A). This may be due to reduced water content in the system with greater lactose concentration. Lactose + lactic acid solution containing $15 \%$ (wt/wt) also showed a prominent peak around $1,650 \mathrm{~cm}^{-1}$. However, this peak has shifted toward a lower wave number $\sim 1,570 \mathrm{~cm}^{-1}$ with the rise in lactose concentration. In addition, the intensity of the peak was reduced substantially up to $40 \%$ (wt/wt) concentration, whereas the $50 \%$ (wt/wt) sample showed an increase in intensity, which confirms that the movement of water molecules was restricted in the presence of lactic acid. In addition, bands around 1,359, 1,408, and $1,448 \mathrm{~cm}^{-1}$ were observed in the $50 \%$ (wt/wt) lactose + lactic acid solution, which could be due to the C-C/C$\mathrm{H}$ aliphatic and $\mathrm{C}-\mathrm{CH}_{3}$ aliphatic stretching vibrations of lactic acid, and $\mathrm{C}-\mathrm{C} / \mathrm{C}-\mathrm{H}$ ring stretching vibrations of lactose, respectively (Pamula et al., 2001). Moreover, 2 other sharp peaks originating around 1,248 and 1,307 $\mathrm{cm}^{-1}$ in the $50 \%$ (wt/wt) lactose + lactic acid solution (Figure 4B) were observed, which were absent in the $50 \%$ (wt/wt) lactose solution. Information about origin of these peaks is lacking in the literature, although Pamula et al. (2001) assigned these peaks to bending vibrations of $\mathrm{O}-\mathrm{H}$ groups. Considering that these peaks were absent in the pure lactose solutions, their appearance may indicate a change in structure of lactose in the presence of lactic acid.

One of the regions of a particular interest is between 3,600 to $3,200 \mathrm{~cm}^{-1}$, which represents the H-bonding region and depicts behavior of water molecules (Wolkers et al., 1998). The presence of lactic acid hinders the removal of water from lactose molecules. This observation may be possibly due to a change in water activities around lactose molecules due to strong interactions with lactic acid and water molecules, which are represented by the H-bonding patterns. In carbohydrates, hydroxyl groups are hardly present in isolation as they are usually involved in intra- and intermolecular H-bonding with other hydroxyl groups (Ottenhof et al., 2003). The shape of these peaks is indicative of constrained water molecules. As the concentration of pure lactose solution rose, the absorbance in the 3,600 to $3,200 \mathrm{~cm}^{-1}$ region declined (Figure 5). A large volume of freely available water molecules exists in the $15 \%$ (wt/wt) lactose solution as compared with the $50 \%$ (wt/wt) lactose solution, which results in a higher mobility of the water molecules. The mobility of the water molecules showed some restrictions with the increase of lactose concentration as in 50\% (wt/wt), highlighting the stronger attractions with lactose molecules. Stronger H-bonding may distort the water molecules (Sharp et al., 2001), inducing the $\mathrm{O}-\mathrm{H}$ stretching vibrations that may lead toward either asymmetrical or symmetrical stretching. Concurrently, the $\mathrm{H}-\mathrm{O}-\mathrm{H}$ bending can also lead to certain structural changes. The appearance of a small peak around $3,600 \mathrm{~cm}^{-1}$ in the $50 \%$ (wt/wt) lactose solution confirmed that the distortion of water molecules around lactose molecules occurred due to symmetrical $\mathrm{O}-\mathrm{H}$ stretching vibrations with gradual increase in concentration likely caused by decline in the number of water molecules competing for available sites.

Addition of lactic acid resulted in disappearance of almost all peaks around 3,600 to $3,200 \mathrm{~cm}^{-1}$, indicating strong attraction between lactic acid and water molecules. On the other hand, 2 prominent peaks around
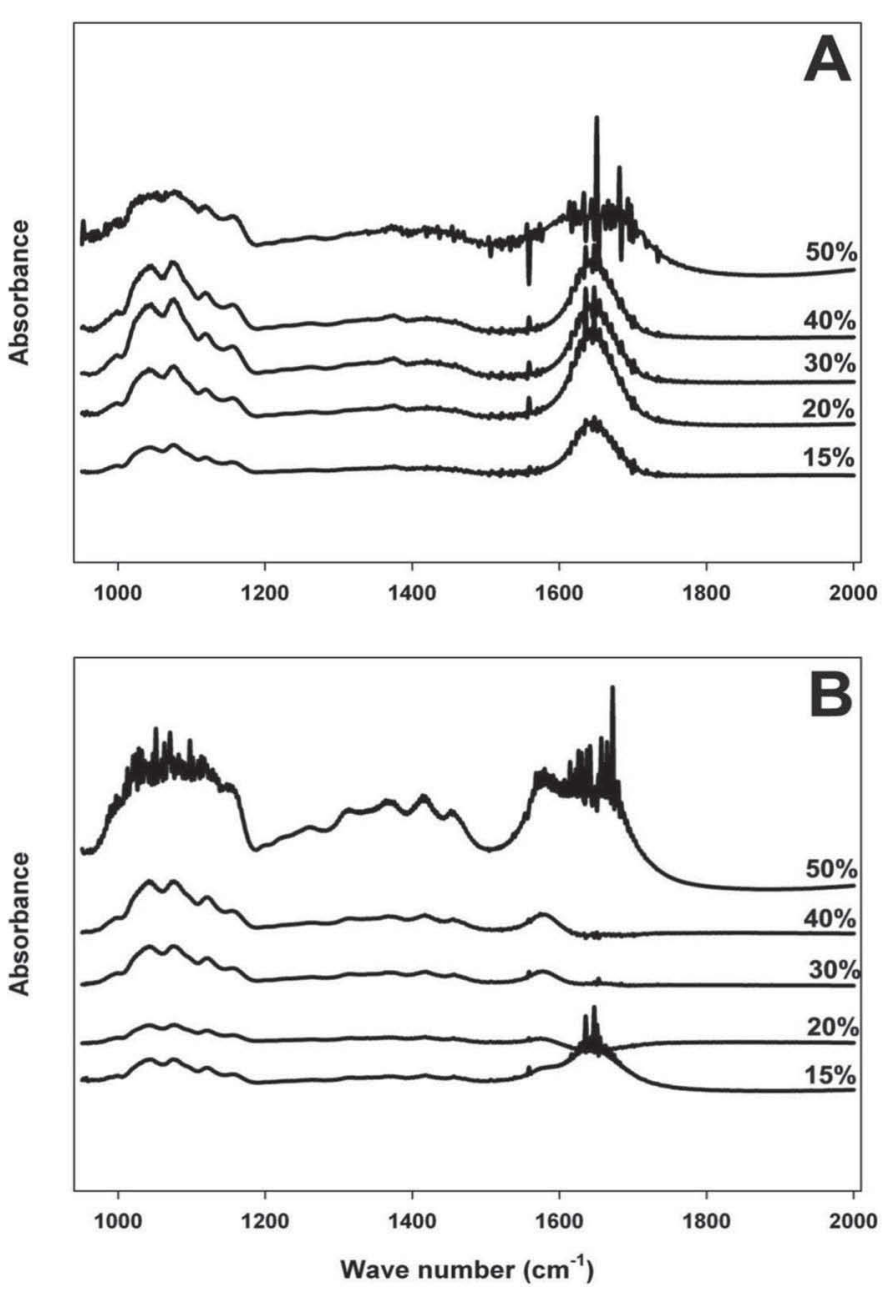

Figure 4. Fourier transform infrared spectra of the 2,000 to 950 $\mathrm{cm}^{-1}$ region in lactose solutions without (A) and with (B) addition of lactic acid as a function of concentration. 
3,000 to $2,900 \mathrm{~cm}^{-1}$ and $3,600 \mathrm{~cm}^{-1}$, respectively, were observed in the $50 \%$ (wt/wt) lactose + lactic acid solution; the former peak was absent in the pure lactose solution at the corresponding concentration (Figure 5B). The peak around 3,000 to $2,900 \mathrm{~cm}^{-1}$ can be described as the stretching vibrations of hydrocarbon groups of lactic acid (Pamula et al., 2001). The latter peak (around 3,600 $\mathrm{cm}^{-1}$ ) was higher in intensity as compared with the pure lactose solution, further highlighting the distortion of water molecules and their mobilities in the presence of lactic acid. During concentration, the amount of lactic acid increases, which consequently results in stronger interactions with a fewer water molecules remaining in the $50 \%$ (wt/wt) solution. This also leads to a greater competition between lactose and lactic acid molecules for available water molecules and subsequently a more disordered physical state.

\section{Lactose Hydration-A Hypothesis}

According to the present study, 2 mechanisms can be proposed to describe the behavior of water molecules around lactose molecules during concentration of pure lactose and lactose solutions with lactic acid. The first mechanism depicts the behavior of lactose during concentration of pure lactose solution (Figures $6 \mathrm{~A}$ and $6 \mathrm{~B})$. The tendency of water to associate with hydrophilic substances is generally defined as hydration or the water binding. Lactose is a hydrophilic solute with an ability to interact strongly with water (Reid and Fennema, 2008). The water molecules can lead to formation of several hydration layers around a lactose molecule (Figure 6A). However, increase in lactose concentration during concentration reduces the amount of available water molecules limited to only one hydration layer, a partially completed hydration layer around a lactose molecule, or both (Figure 6B). In addition, these water molecules are now strongly attracted to lactose as indicated by the reduced stretching vibrations. These strong interactions can induce partial structural changes of the hydrophilic solute itself as observed with the FTIR results and was consistent with Reid and Fennema (2008). This effect was more pronounced with rise in concentration and limited amount of available water to engage in these attractions, which consequently leads to a distortion effect of lactose molecules attempting to occupy their hydrophilic sites and overall a structural change. These structurally changed lactose molecules have shown a great tendency toward accelerating water removal.

The second mechanism describes behavior of lactose in the presence of lactic acid during concentration. Addition of lactic acid to a lactose and water solution enhances the attraction forces between lactic acid and
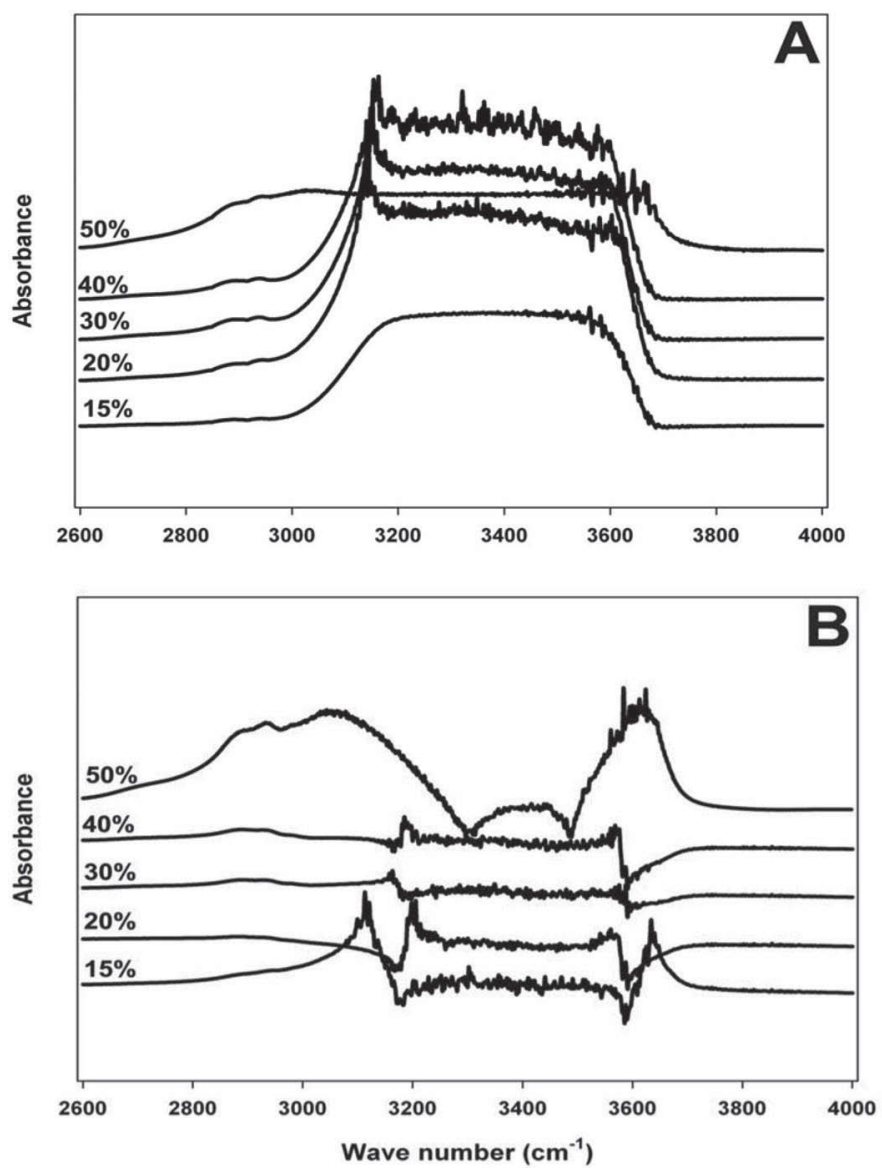

Figure 5. Fourier transform infrared spectra of lactose (A) and lactose + lactic acid (B) as a function of concentration in the range of 4,000 to $2,600 \mathrm{~cm}^{-1}$.

water molecules, which in turn reduces the mobility of the water molecules (Timasheff, 2002). Subsequently, lactic acid further interacts with lactose, resulting in change of the chemical potentials of both compounds. Furthermore, formation of hydrated $\mathrm{H}_{3} \mathrm{O}^{+}$ions in the presence of lactic acid leads to strong $\mathrm{H}$ bonding with lactose molecules and subsequently creation of a strong hydration layer (Figure 6C). This effect is more pronounced at higher concentrations where fewer water molecules are available to form a hydration layer. These water molecules are also strongly attached to the lactose molecules due to increased reactivity of the $\mathrm{H}_{3} \mathrm{O}^{+}$ions. The hydration layer would consequently be strongly attracted to the lactose molecules, which in turn requires greater energy to remove the hydration layer from lactose molecules. These strong interactions induce an evident structural change of lactose molecules, which are quite different and prominent than those observed for pure lactose systems. Furthermore, the affinity of lactic acid to bind water molecules is much greater than that of lactose. This may lead to strong attractions 
between water molecules and lactic acid and creation of a hydration complex, which consequently may attach to a lactose molecule (Figure 6D).

\section{CONCLUSIONS}

Compositional differences between acid and sweet whey hinder further processing of acid whey mainly due to the presence of amorphous lactose. In pure lactose solution, enthalpy of water dehydration was reduced with increase in lactose concentration. The addition of lactic acid led to increase in water dehydration enthalpy, indicating that the presence of lactic acid hindered removal of water from lactose. Lactic acid as a highly hydrophilic compound appears to strongly interact with water molecules. This may lead to formation of a strong hydration layer consisting of lactic acid and $\mathrm{H}_{3} \mathrm{O}^{+}$ions around lactose molecules via exceptionally strong $\mathrm{H}$ bonds, which thereby result in restricted water mobility, a change in a structure of lactose, or both. This phenomenon appears responsible for limited lactose crystallization where a high energy input appeared necessary to crystallize lactose. The observations indicate that partial or complete removal of lactic acid from acid whey may improve lactose crystallization and thereby the ability of acid whey to be

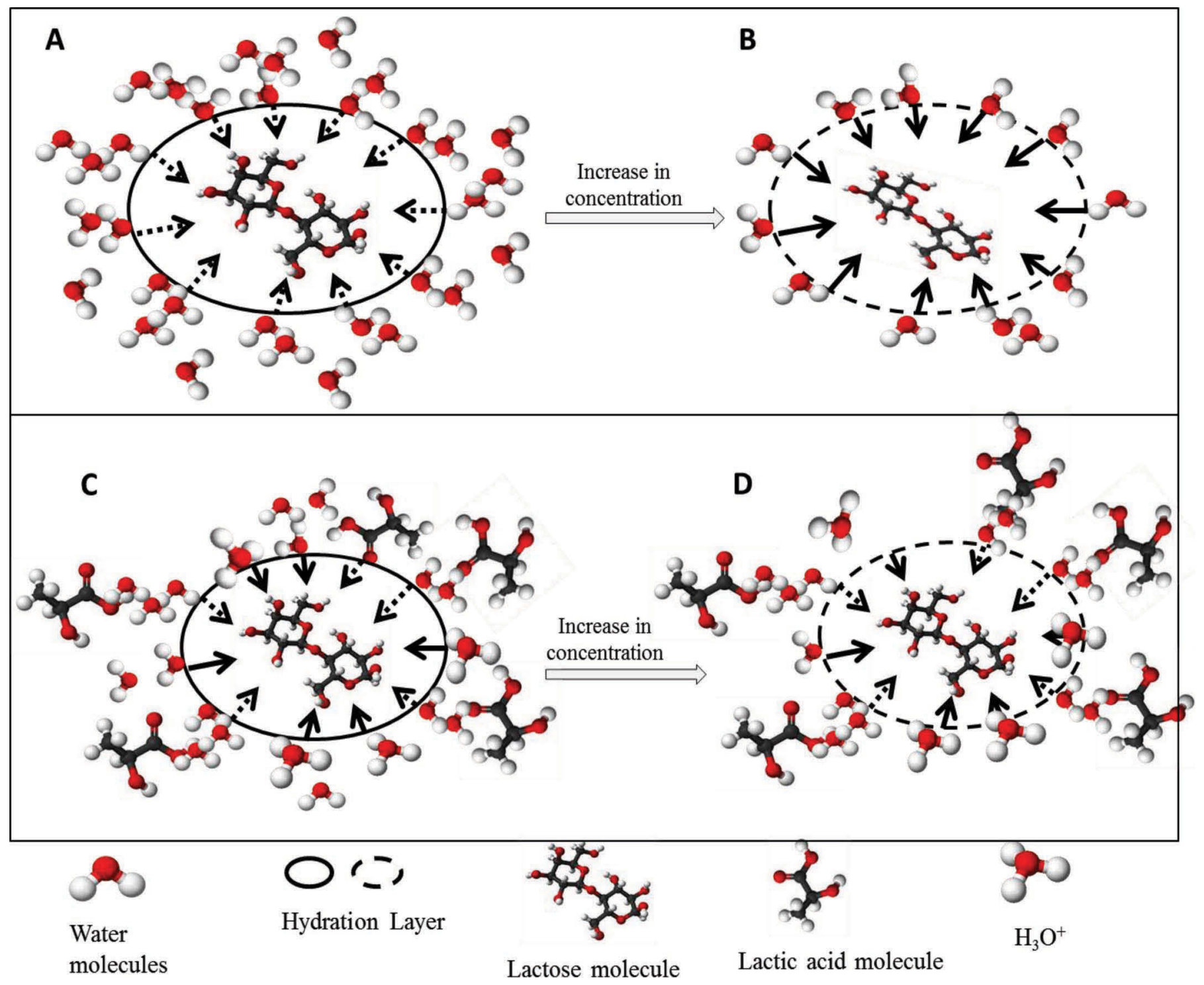

Figure 6. Schematic representation of the lactose hydration mechanism 1 (A and B) of pure lactose solutions and lactose hydration mechanism $2(\mathrm{C}$ and $\mathrm{D})$ with the addition of lactic acid as a function of concentration. Solid arrows indicate a much stronger attraction, whereas dashed arrows indicate a weaker attraction; a solid circle indicates the stronger hydration layer, whereas a dashed circle indicates the weaker hydration layer. Color version available online. 
processed. Lactic acid removal could be achieved by membrane processing; however, several questions still remain to be answered. Obviously, from the current data, it was apparent that the presence of $1 \%$ (wt/ wt) lactic acid in acid whey plays an important role in lactose crystallization during the evaporation process. Therefore, a threshold of lactic acid concentration that would allow for proper lactose crystallization needs to be established. Moreover, the role of the main minerals such as $\mathrm{Ca}$ and proteins may need to be determined as they may hinder or facilitate lactose crystallization.

\section{ACKNOWLEDGMENTS}

Rangani Wijayasinghe thanks the Research Training Scheme for her MS scholarship.

\section{REFERENCES}

Anslyn, E. V., and D. A. Dougherty. 2006. Strain and stability. Pages 65-76 in Modern Physical Organic Chemistry. E. V. Anslyn and D. A. Dougherty, ed. University Science Books, Herndon, VA.

Aubuchon, S. R., and L. Thomas. 2007. Detection and quantification of pharmaceutical amorphous content. Pages 10\#125/1-10\#125/6 in Proc. 35th NATAS Annu. Conf. Thermal Analysis and Applications, East Lansing, MI.

Belitz, H. D., W. Grosch, and P. Schieberle. 2009. Food Chemistry. 4th ed. Springer-Verlag, Heidelberg, Germany.

Bhandari, B. 2008. Crystallization of amorphous lactose in the presence lactic acid. Factors affecting crystallization of amorphous solids. International Union of Food Science and Technology, Shanghai, China.

Bhargava, A., and P. Jelen. 1996. Lactose solubility and crystal growth as affected by mineral impurities. J. Food Sci. 61:180-184.

Chandrapala, J., M. C. Duke, S. R. Gray, B. Zisu, M. Weeks, M. Palmer, and T. Vasiljevic. 2015. Properties of acid whey as a function of $\mathrm{pH}$ and temperature. J. Dairy Sci. 98:4352-4363.

Chiou, D., T. A. G. Langrish, and R. Braham. 2008. The effect of temperature on the crystallinity of lactose powders produced by spray drying. J. Food Eng. 86:288-293.

De Wit, J. N. 2001. Lecturer's Handbook on Whey and Whey Products. European Whey Products Association, Brussels, Belgium.

Ganzle, M., G. Haase, and P. Jelen. 2008. Lactose crystallization: Hydrolysis and value added derivatives. Int. Dairy J. 18:685-694.

Haque, M. K., and Y. H. Roos. 2004. Water plasticization and crystallization of lactose in spray-dried lactose/protein mixtures. J. Food Sci. 69:23-29.

Haque, M. K., and Y. H. Roos. 2006. Differences in the physical state and thermal behaviour of spray-dried and freeze-dried lactose and lactose/protein mixtures. Innov. Food Sci. Emerg. Technol. $7: 62-73$.

Islam, M. I. U., and T. A. G. Langrish. 2010. An investigation into lactose crystallization under high temperature conditions during spray drying. Food Res. Int. 43:46-56.

Jamshidian, M., E. A. Tehranu, M. Imran, M. Jacquot, and S. Desorby. 2010. Poly-lactic acid: Production, applications, nanocomposites and release studies. Comp. Rev. Food Sci. Food Saf. 9:552-571.
Jelen, P., and S. T. Coulter. 1973a. Effects of certain salts and other whey substances on the growth of lactose crystals. J. Food Sci. 38:1186-1189

Jelen, P., and S. T. Coulter. 1973b. Effects of supersaturation and temperature on the growth of lactose crystals. J. Food Sci. 38:1182-1185.

Maltini, E., M. Anese, and I. Shtylla. 1967. State diagram of some organic acid-water systems of interested in food. Cryo Lett. 18:263

Mullin, J. W. 1979. Crystal growth in pure and impure systems. Pages 93-103 in S. J. Jancic and E. J. de Jong, ed. Industrial Crystallization. North-Holland Publishing Co., New York, NY.

Omar, A. M. E., and Y. H. Roos. 2007. Glass transition and crystallization behaviour of freeze-dried lactose-salt mixtures. LWT 40:536-543.

Ottenhof, M. A., W. MacNaughtan, and I. A. Farhat. 2003. FTIR study of state and phase transitions of low moisture sucrose and lactose. Carbohydr. Res. 338:2195-2202.

Pamula, E., M. Blazewicz, C. Paluszkiewicz, and P. Dobrzynski. 2001. FTIR study of degradation products of aliphatic polyesters-carbon fibre composites. J. Mol. Struct. 556:69-75.

Punitha, S., R. Uvarani, A. Panneerselvam, and S. Nithiyanantham. 2014. Physico-chemical studies on some saccharides in aqueous cellulose solutions at different temperatures-Acoustical and FTIR analysis. J. Saudi Chem. Soc. 18:657-665.

Reid, S. D., and R. O. Fennema. 2008. Water and ice. Pages 17-83 in Fennema's Food Chemistry. 4th ed. S. Damodaran, L. K. Parkin and R. O. Fennema, ed. Taylor \& Francis Group, LLC, Boca Raton, FL.

Roos, Y., and M. Karel. 1990. Differential scanning calorimetry study of phase transitions affecting the quality of dehydrated raw materials. Biotechnol. Prog. 6:159-163.

Saffari, M., and T. Langrish. 2014. Effect of lactic acid in-process crystallization of lactose/protein powders during spray drying. J. Food Eng. 137:88-94.

Schmidt, R. H., V. S. Packard, and H. A. Morris. 1984. Effect of processing on whey protein functionality. J. Dairy Sci. 67:2723-2733.

Sharp, K. A., B. Madam, E. Manas, and J. M. Vanderkooi. 2001. Water structure changes induced by hydrophobic and polar solutes revealed by simulations and infrared spectroscopy. J. Chem. Phys. 114:1791-1796.

Solis-Oba, M., O. Teniza-Garcia, M. Rojas-Lopez, R. Delgado-Macuil, J. Diaz-Reyes, and R. Ruiz. 2011. Application of infrared spectroscopy to the monitoring of lactose and protein from whey after ultra and nano filtration process. J. Mex. Chem. Soc. 55:190-193.

Timasheff, S. N. 2002. Protein hydration, thermodynamic binding, and preferential hydration. Biochemistry 41:13473-13482.

Vasiljevic, T., and P. Jelen. 1999. Temperature effect on behaviour of minerals during ultrafiltration of skim milk and acid whey. Milchw. Milk Sci. Int. 54:243-246.

Velazquez, G., A. Herrera-Gomez, and M. O. Martin-Polo. 2003. Identification of bound water through infrared spectroscopy in methylcellulose. J. Food Eng. 59:79-84.

Von Hippel, P. H., and T. Schleich. 1969. The effects of neutral salts on the structure and conformational stability of macromolecules in solution. Pages 417--574 in Structure and Stability of Biological Macromolecules. S. N. Timasheff and G. D. Fasman, ed. Marcel Dekker, New York, NY.

Wolkers, W. F., H. Oldenhof, M. Alberda, and F. A. Hoekstra. 1998 A Fourier transform infrared micro-spectroscopy study of sugar glasses: Application to anhydrobiotic higher plant cells. Biochim. Biophys. Acta 1379:83-96.

Yazdanpanah, N., and T. A. G. Langrish. 2011. Crystallization and drying of milk powder in a multiple-stage fluidized bed dryer. Int. J. Drying Tech. 29:1046-1057. 